\title{
Intervenção educativa sobre parada cardiorrespiratória intra-hospitalar: conhecimento dos profissionais de enfermagem de unidades médico-cirúrgicas*
}

\author{
Reginaldo Passoni dos Santos ${ }^{1}$, Lili Marlene Hofstatter ${ }^{2}$, Ariana Rodrigues da Silva Carvalho ${ }^{3}$, \\ Sidnei Roberto Alves ${ }^{4}$
}

\author{
* Oriundo do Trabalho de Conclusão de \\ Residência: "Efeito de intervenções \\ educativas no conhecimento dos profissionais \\ de enfermagem sobre parada \\ cardiorrespiratória e ressuscitação \\ cardiopulmonar", apresentado ao Programa \\ de Residência em Enfermagem da \\ Universidade Estadual do Oeste do Paraná. \\ ${ }^{1}$ Enfermeiro. Discente do Programa de Pós- \\ Graduação Stricto senu em Biociências e \\ Saúde, nível Mestrado, da Universidade \\ Estadual do Oeste do Paraná. Cascavel, PR, \\ Brasil. E-mail: regi-pas@hotmail.com. \\ ${ }^{2}$ Enfermeira, Mestre em Enfermagem \\ Fundamental. Professora Titular da \\ Universidade Estadual do Oeste do Paraná. \\ Cascavel, PR, Brasil. E-mail: \\ Im_hofstatter@yahoo.com.br. \\ ${ }^{3}$ Enfermeira, Doutora em Enfermagem \\ Fundamental. Professora Adjunto da \\ Universidade Estadual do Oeste do Paraná. \\ Cascavel, PR, Brasil. E-mail: \\ arscarvalho@gmail.com. \\ ${ }^{4}$ Enfermeiro, Mestre em Promoção da Saúde. \\ Enfermeiro Assistencial no Pronto Socorro do \\ Hospital Universitário da Universidade \\ Estadual do Oeste do Paraná. Cascavel, PR, \\ Brasil. E-mail: sidneiunioeste@gmail.com.
}

Recebido: 24/02/2016.

Aceito: 22/05/2017.

Publicado: 01/10/2017.

Como citar esse artigo:

Santos RP, Hofstatter LM, Carvalho ARS, Alves SR. Intervenção educativa sobre parada cardiorrespiratória intra-hospitalar: conhecimento dos profissionais de enfermagem de unidades médico-cirúrgicas. Rev. Eletr. Enf. [Internet]. 2017 [acesso em: ____;19:a25. Disponível em: http://dx.doi.org/10.5216/ree.v19.39945.

\section{RESUMO}

Esta pesquisa objetivou avaliar o efeito de uma intervenção educativa sobre parada cardiorrespiratória no conhecimento teórico de profissionais de enfermagem em unidades de internação médicocirúrgica. Estudo quase experimental, desenvolvido com profissionais atuantes em duas unidades de internação, de um hospital universitário público do Paraná. Como intervenções educativas, realizaram-se treinamentos teórico-práticos. Aplicaram-se um questionário antes $\mathrm{e}$, imediatamente após os treinamentos. Consideraram-se valores de $p<0,05$, como significativos. Dos 47 profissionais presentes nas unidades, 37 (78,72\%) participaram do pré-teste e 32 (68,09\%) do pós-teste. Identificou-se prevalência de mulheres, com idade entre 31 e 45 anos, que trabalhavam em sua unidade laboral e apresentavam tempo de formação profissional maior que cinco anos. Os escores obtidos após as intervenções educativas (pós-teste) apresentaram aumento estatisticamente significativo $(p<0,0001)$, em relação ao pré-teste. A intervenção educativa colaborou, positivamente, no conhecimento teórico dos profissionais de enfermagem sobre parada cardiorrespiratória.

Descritores: Parada Cardíaca; Ressuscitação Cardiopulmonar; Capacitação em Serviço; Enfermagem.

\section{INTRODUÇÃO}

Pacientes com idade avançada, tempo de internação prolongado, doenças crônicas, bem como aqueles hospitalizados por situações/agravos agudos, cujo manejo clínico se deu com pouca acurácia, apresentam risco aumentado para 
sucumbirem em parada cardiorrespiratória intra-hospitalar $(P C R I H)^{(1-3)}$. Dessa forma, cabe destacar que a ocorrência e o desfecho do evento estão relacionados, dentre outros fatores, à assistência que lhes é ofertada pelos profissionais de saúde $\mathrm{e}^{(2-4)}$.

Em estudo recente desenvolvido nos Estados Unidos da América (EUA), pesquisadores apontaram que nos últimos 10 anos houve importante incremento na sobrevida dos indivíduos que sofreram PCRIH ${ }^{(5)}$. Por outro lado e, apesar dos esforços empreendidos, no Brasil $^{(6)}$ e em outras regiões do mundo ${ }^{(7-9)}$, as taxas de sobrevida pós-PCRIH ainda são baixas.

Importante salientar que os principais fatores associados à PCRIH, e ao seu desfecho, perpassam pela tríade "estrutura, processo e resultados", a qual se relaciona tanto com a assistência profissional propriamente dita, quanto a aspectos globais das instituições de saúde ${ }^{(3,5,10)}$.

Sobre a assistência profissional, compreende-se que indicadores de desfechos da PCRIH são influenciados pelo preparo da equipe de saúde para a rápida e eficaz identificação do evento, bem como pela adequada abordagem ao sujeito, no momento da reanimação cardiopulmonar (RCP) ${ }^{(10-11)}$. Dessa forma, os investimentos contínuos na educação permanente dos profissionais apresentam-se necessários ${ }^{(1-4)}$.

No bojo dessa discussão, instituiu-se em 2009 a Política Nacional de Educação Permanente em Saúde (PNEPS). Concatenada aos princípios e diretrizes do Sistema Único de Saúde (SUS) brasileiro, a PNEPS tem, dentre suas propostas, o incentivo à intervenções educativas junto aos trabalhadores de saúde, no intuito de melhorar a qualidade e os desfechos da assistência prestada pelos profissionais no âmbito do SUS ${ }^{(12)}$.

Sobre a educação permanente desenvolvida com foco no aprimoramento da atuação profissional em $P C R$, estudiosos ${ }^{(3-4,10)}$ relatam que é preciso que seja identificado o grau de conhecimento dos trabalhadores, pois isso favorece a sistematização das ações educativas e o levantamento das necessidades pontuais de capacitação. Do mesmo modo, faz-se mister que se avalie o efeito das intervenções ${ }^{(13)}$, ou seja, das atividades educativas propostas para essa atualização.

Frente ao exposto, o presente estudo teve seu desenvolvimento norteado pela seguinte questão: Qual o efeito de intervenções educativas sobre PCRIH, no conhecimento dos profissionais de enfermagem?

Com base na literatura pertinente ${ }^{(13-15)}$ e na vivência prática dos pesquisadores no campo de estudo, a hipótese inicialmente levantada foi de que a equipe de enfermagem apresenta déficit de conhecimento teórico sobre a temática, entretanto, intervenções educativas podem mostrar-se bastante profícuas na atualização e resgate de saberes dos profissionais.

Para testar a referida hipótese, objetivou-se avaliar o efeito de uma intervenção educativa sobre PCRIH no conhecimento teórico dos profissionais de enfermagem em unidades de internação de clínica médicocirúrgica de um hospital universitário público, no interior do Paraná.

\section{MÉTODO}

Trata-se de um estudo quase experimental, com grupo único não equivalente, com pré e pós-teste. A pesquisa foi desenvolvida em um hospital universitário público do interior do Paraná, entre os meses 
de julho e dezembro de 2015. O referido hospital possui 195 leitos, é referência em trauma e cirurgia geral e, possui 25 municípios em sua área de abrangência.

Participaram dessa investigação, enfermeiros, auxiliares e técnicos de enfermagem, que desempenhavam suas práticas laborais em duas unidades de internação de clínica médico-cirúrgica que atendem número considerável de PCRIH. Uma das unidades é composta por 25 leitos e os profissionais realizam assistência à pacientes clínicos e cirúrgicos das especialidades de neurologia, ortopedia e medicina vascular. Já na outra, com 28 leitos, prestam-se cuidados à pacientes clínicos e cirúrgicos das seguintes especialidades: clínica médica, cirurgia geral e cardiologia (clínica e cirúrgica). Vale destacar que, as duas unidades apresentam um efetivo de equipe de enfermagem de 59 profissionais.

Foram estabelecidos os seguintes critérios de inclusão para a participação no estudo: ser membro da equipe de enfermagem das unidades selecionadas para o estudo e atuando nessas unidades por um tempo igual ou superior a seis meses; ter vínculo empregatício com a instituição e; participar das intervenções educativas, respondendo ao instrumento de avaliação do conhecimento teórico sobre PCRIH. Foram considerados excluídos da amostra aqueles que se encontravam afastados de suas práticas laborais, seja por folga, férias, atestados ou quaisquer outros.

O cenário do treinamento, propriamente dito, foi uma sala de uso multiprofissional da instituição, em uma das unidades do estudo, destinada, exclusivamente, à práticas didático-pedagógicas.

$\mathrm{Na}$ instituição pesquisada há cinco turnos laborais, sendo que os profissionais participaram da intervenção em seus respectivos turnos de trabalho. Não obstante, aqueles que não conseguiram participar em seu horário de trabalho puderam fazer parte do treinamento em seu contra turno.

A intervenção educativa se constituiu de encontros teórico-práticos, totalizando cinco treinamentos, ou seja, um treinamento para cada turno de trabalho, visando atender às necessidades de cada um dos grupos. Em cada grupo de profissionais treinados, havia o quantitativo mínimo de três e máximo 10 participantes. Os treinamentos tinham duração de duas horas cada um, igualmente apresentados aos grupos, diferindo apenas quanto ao horário de realização, devido à disponibilidade dos participantes.

Para o desenvolvimento dos treinamentos, o conteúdo teórico foi apresentado no formato de aula expositiva-dialogada, com apresentação de slides em multimídia. Além disso, foram realizadas simulações realísticas nas quais os participantes tinham acesso a bonecos para revisarem as habilidades necessárias ao atendimento da PCRIH.

A intervenção foi aplicada seguindo-se um roteiro previamente elaborado pelos pesquisadores, com fundamentação nas Diretrizes 2010 da American Heart Association (AHA) para RCP e Cuidados Cardiovasculares de Emergência (CCE) ${ }^{(16)}$, bem como a I Diretriz de RCP e CCE da Sociedade Brasileira de Cardiologia $(S B C)^{(17)}$. Vale ressaltar que no período de realização desses treinamentos, a atualização das Diretrizes 2015 da AHA ainda não tinha sido publicada.

Em adição à intervenção educativa, os participantes receberam um guia teórico, impresso, na forma de manual, que apresentava os mesmos tópicos trabalhados durante os treinamentos. Nesse sentido, cabe 
destacar que não houve consulta a esse material para responder ao instrumento. O mesmo era entregue aos participantes na medida em que estes fossem finalizando o preenchimento do questionário, uma vez que o guia teve a intenção de ser um compilado de informações científicas fidedignas sobre PCRIH/RCP, para consulta no dia-a-dia de trabalho, conforme necessidades individuais.

A coleta de dados ocorreu no mês de setembro de 2015 e deu-se por meio de um instrumento construído e validado (aparência e conteúdo), apresentando-se na forma de questionário autoaplicável, semiestruturado, composto por duas partes: uma para caracterização da amostra e outra para avaliação do conhecimento sobre PCRIH/RCP.

Para validação do referido instrumento, o mesmo foi analisado por cinco juízes, todos graduados em Enfermagem, com titulação mínima de especialista e, com notório saber téorico e prático no que diz respeito ao atendimento de pacientes em pronto-socorro, emergência hospitalar e unidade de terapia intensiva.

Importante destacar, que o instrumento foi considerado válido para utilização quando o cálculo do percentual de concordância entre os juízes foi maior que $90 \%$ e o índice de validação de conteúdo mais que 0,90 pontos, conforme proposto pela literatura ${ }^{(18)}$.

A primeira parte do questionário, a caracterização da amostra estudada, foi composta pelas seguintes variáveis: idade; tempo de trabalho na unidade; tempo de formação na função laboral; formação acadêmica (exceto a formação mínima exigida à função desempenhada na instituição); participação em educação permanente (especificamente, sobre Suporte Básico de Vida - SBV - e/ou Suporte Avançado de Vida Cardiovascular - SAVC); frequência de atuação em situação de PCRIH (na unidade laboral em que o indivíduo se encontrava).

Na segunda parte do instrumento, constavam as questões que objetivavam avaliar o conhecimento teórico dos profissionais sobre PCRIH, composta por 14 perguntas de múltipla escolha $(A, B, C$ e $D)$, sendo sete sobre SBV e sete sobre SAVC (Quadro 1), devendo os participantes assinalar aquela que considerasse como correta. Algumas questões apresentavam mais de uma alternativa certa, dessa forma, orientou-se os participantes que para uma mesma questão eles poderiam assinalar mais de uma alternativa, caso julgassem necessário/pertinente.

Quadro 1: Temática das questões aplicadas aos profissionais. Cascavel-PR, Brasil, 2015.

\begin{tabular}{|l|l|}
\hline \multicolumn{1}{|c|}{ Grupo de questões sobre SBV: } & \multicolumn{1}{c|}{ Grupo de questões sobre SAVC: } \\
\hline Q1. Como detectar PCR & Q8. Posicionamento das pás na DE \\
\hline Q2. Primeira atitude após constatar PCR & Q9. Carga elétrica mínima para DE \\
\hline Q3. Posicionamento das mãos na MCE & Q10. Carga elétrica máxima para DE \\
\hline Q4. Posicionamento corporal para MCE & Q11. Vias de administração dos fármacos \\
\hline Q5. Ventilação do paciente com VAA & Q12. Fármacos para reversão da PCR \\
\hline Q6. Ventilação do paciente sem VAA & Q13. Ação principal dos fármacos \\
\hline Q7. Sequência do SBV para adultos & Q15. Sequência do SVAC para adultos \\
\hline
\end{tabular}

$\mathrm{SBV}$ = suporte básico de vida; $\mathrm{SAVC}=$ suporte avançado de vida cardiovascular; $\mathrm{Q}$ = questão; $\mathrm{PCR}$ = parada cardiorrespiratória; $\mathrm{MCE}=$ massagem cardíaca externa; VAA = via aérea avançada; $D E=$ desfibrilação externa.

Os participantes foram convidados a preencherem o questionário completo em dois momentos: préintervenção e, imediatamente após o treinamento (pós-intervenção). Para mascarar a semelhança do 
questionário pré e pós-intervenção, as questões no pós-teste sofreram alteração na ordem sequencial em que foram apresentadas no pré-teste.

Tabularam-se os dados coletados em planilha do programa Microsoft Excel ${ }^{\circ}$, versão 2010, exportandoos posteriormente para o programa estatístico " $\mathrm{R}^{\text {"(19) }}$. Para examinar os dados obtidos pelo preenchimento da primeira parte do questionário, realizou-se estatística simples com frequências relativas e absolutas. Nessa mesma direção, aos dados provenientes da segunda parte aplicou-se estatística analítica. Para tanto, atribuiu-se um ponto a cada questão, sendo este dividido em partes iguais entre as alternativas, nos casos das questões que constavam mais de uma resposta certa, sendo que o questionário completo apresentava escore que poderia variar de zero a 14 pontos. Quanto maior a pontuação do participante, melhor seu conhecimento teórico sobre a temática abordada.

Para avaliação do efeito das intervenções educativas no conhecimento teórico dos profissionais, realizaram-se comparações pareadas entre os pontos obtidos antes (pré-teste) e depois (pós-teste) do treinamento (intervenção educativa), por meio do teste paramétrico de $t$-Student. Para tanto, realizaram-se o teste de Shapiro-Wilk para checar os pressupostos de normalidade e o teste $F$ para conferência de homocedasticidade. Nas situações em que estes dois últimos pressupostos não foram conferidos, aplicou-se o teste não paramétrico de Wilcoxon. Foram considerados valores de $p$ menores que $(<) 0,05$ como estatisticamente significativos.

Para a condução da pesquisa, obteve-se aprovação prévia pelo Comitê de Ética em Pesquisa com seres humanos da instituição a qual os pesquisadores estão vinculados, sendo emitido parecer favorável a sua execução sob o № 1.124 .574 e Certificado de Apresentação para Apreciação Ética com no 46193115.5.0000.0107. Todos os participantes assinaram o Termo de Consentimento Livre e Esclarecido, em duas vias, uma ficando em posse dos pesquisadores e outra com o participante, conforme Resolução no 466/2012 do Conselho Nacional de Saúde ${ }^{(20)}$.

\section{RESULTADOS}

Dos 59 trabalhadores em enfermagem das unidades em questão neste estudo, 12 (20,33\%) não se encontravam em exercício laboral em nenhum dos cinco momentos de intervenção educativa. Assim, dos 47 profissionais presentes nas unidades, participaram da pesquisa 37 (78,72\%) profissionais no momento préintervenção, sendo 10 enfermeiros e 27 técnicos/auxiliares.

Na fase pós-intervenção, 32 (68,09\% do efetivo) profissionais preencheram o instrumento de coleta de dados, dos quais cinco eram enfermeiros e 27 técnicos/auxiliares, sendo que 10 (21,28\%) profissionais recusaram preencher o pré-teste e 15 (31,91\%) o pós-teste.

Dentre os participantes, identificou-se prevalência de indivíduos do sexo feminino $(28 ; 87,5 \%)$, com idade entre 31 e 45 anos $(23 ; 71,88 \%)$, que trabalhavam em sua unidade laboral e apresentavam tempo de formação profissional maior que cinco anos.

Com relação à formação acadêmica, entre os enfermeiros $80 \%(n=8)$ já possuíam ao menos uma pós- 
graduação (lato senso e/ou stricto senso) na área da saúde. Entre os técnicos/auxiliares, $37 \%(n=10)$ tinham uma graduação (relacionada ou não à área da saúde) e $29,7 \%$ ( $n=8)$ possuíam o título acadêmico de enfermeiros.

Quando questionados sobre educação permanente voltada ao SBV/SAVC, 60\% ( $n=6)$ dos enfermeiros e 48,1\% ( $n=13)$ dos técnicos/auxiliares afirmaram terem realizado há mais de quatro anos. Por outro lado, todos os profissionais mencionaram já terem atuado em situação de PCR na unidade assistencial que trabalham, sendo que $90 \%(n=9)$ dos enfermeiros e $88,9 \%(n=24)$ dos técnicos/auxiliares atuaram em, pelo menos, quatro ocasiões.

Com relação à avaliação do conhecimento, os enfermeiros apresentaram acréscimos, estatisticamente significativos, na média de pontos obtidos no pós-teste em sete $(50 \%)$ das 14 questões, sendo observada maior diferença em "Q1" ( $p$-valor: 0,035) e "Q11" (p-valor: 0,008). Por outro lado, auxiliares e técnicos de enfermagem obtiveram diferenças estatísticas em 12 (85,71\%) questões. Para essa subcategoria, apenas as médias em “Q9" ( $p$-valor: 0,146) e "Q14" ( $p$-valor: 0,65) não apresentaram diferenças significativas.

$\mathrm{Na}$ avaliação da média de pontos por grupo de questões, tanto enfermeiros quanto auxiliares e técnicos apresentaram aumento significativo nos pontos obtidos após os treinamentos, como pode ser observado na Tabela 1.

Tabela 1: Média e desvio padrão de enfermeiros, auxiliares e técnicos obtidos no pré e pós-teste teste, segundo a questão e o grupo de questões. Cascavel, PR, Brasil, 2015.

\begin{tabular}{|c|c|c|c|c|c|c|}
\hline \multirow{3}{*}{ Questão } & \multicolumn{3}{|c|}{ Enfermeiros } & \multicolumn{3}{|c|}{ Técnicos e Auxiliares } \\
\hline & $\begin{array}{l}\text { Pré-teste } \\
(n=10)\end{array}$ & Pós-teste (n=5) & ${ }^{*} p$ & Pré-teste (n=27) & Pós-teste (n=27) & ${ }^{*} \boldsymbol{p}$ \\
\hline & Média (DP) & Média (DP) & & Média (DP) & Média (DP) & \\
\hline Q1 & $0,00(0,00)$ & $1,00(0,00)$ & $0,018^{\dagger}$ & $0,37(0,19)$ & $0,77(0,42)$ & $<0,0001$ \\
\hline Q2 & $0,20(0,44)$ & $0,80(0,44)$ & 0,035 & $0,25(0,44)$ & $0,70(0,46)$ & 0,001 \\
\hline Q3 & $0,80(0,44)$ & $0,80(0,44)$ & 0,500 & $0,62(0,49)$ & $0,88(0,32)$ & 0,025 \\
\hline Q4 & $0,40(0,54)$ & $0,80(0,44)$ & 0,088 & $0,48(0,50)$ & $0,81(0,39)$ & 0,004 \\
\hline Q5 & $0,40(0,22)$ & $0,60(0,22)$ & 0,088 & $0,48(0,16)$ & $0,57(0,22)$ & 0,048 \\
\hline Q6 & $0,80(0,44)$ & $1,00(0,00)$ & 0,187 & $0,77(0,42)$ & $0,92(0,26)$ & 0,021 \\
\hline Q7 & $0,40(0,54)$ & $1,00(0,00)$ & 0,035 & $0,29(0,46)$ & $0,85(0,36)$ & $<0,0001$ \\
\hline $\begin{array}{c}\text { Média Grupo } \\
\text { SBV }\end{array}$ & $0,42(0,29)$ & $0,85(0,15)$ & 0,007 & $0,46(0,18)$ & $0,78(0,11)$ & 0,001 \\
\hline Q8 & $0,20(0,44)$ & $0,40(0,54)$ & 0,310 & $0,00(0,00)$ & $0,29(0,46)$ & 0,001 \\
\hline Q9 & $0,40(0,54)$ & $0,80(0,44)$ & 0,187 & $0,40(0,50)$ & $0,55(0,50)$ & 0,146 \\
\hline Q10 & $0,20(0,44)$ & $0,80(0,44)$ & 0,035 & $0,14(0,36)$ & $0,92(0,26)$ & $<0,0001$ \\
\hline Q11 & $0,00(0,00)$ & $0,80(0,44)$ & 0,008 & $0,00(0,00)$ & $1,00(0,00)$ & $<0,0001^{\dagger}$ \\
\hline Q12 & $0,20(0,44)$ & $0,80(0,44)$ & 0,035 & $0,07(0,26)$ & $0,88(0,32)$ & $<0,0001$ \\
\hline Q13 & $0,00(0,00)$ & $0,60(0,54)$ & 0,035 & $0,22(0,42)$ & $0,59(0,50)$ & 0,002 \\
\hline Q14 & $0,10(0,13)$ & $0,40(0,37)$ & 0,088 & $0,36(0,28)$ & $0,48(0,31)$ & 0,065 \\
\hline $\begin{array}{c}\text { Média Grupo } \\
\text { SAVC }\end{array}$ & $0,15(0,13)$ & $0,65(0,19)$ & 0,0003 & $0,17(0,16)$ & $0,67(0,26)$ & 0,004 \\
\hline
\end{tabular}

O resultado obtido pelos profissionais na avaliação geral, sem diferenciar a subcategoria, são apresentados na Figura 1. 


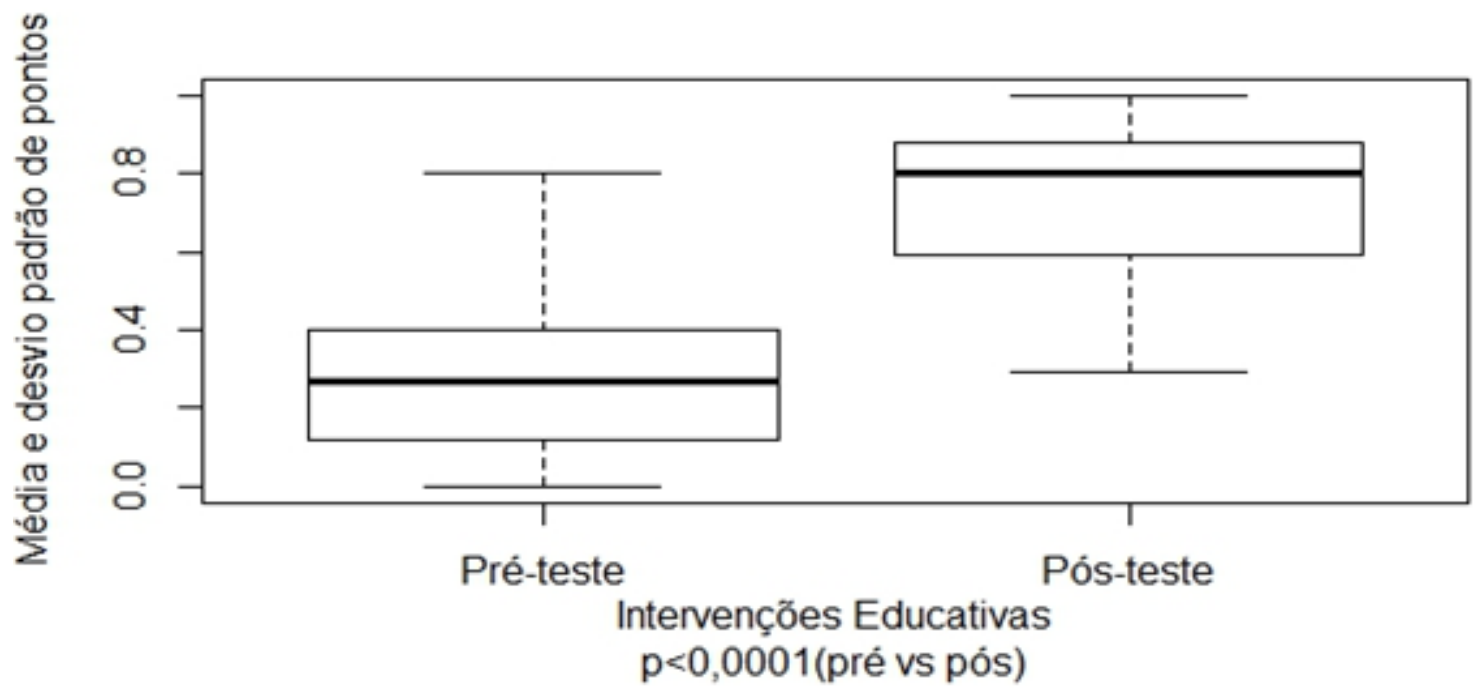

Figura 1: Efeito das intervenções educativas no conhecimento teórico dos profissionais de enfermagem (enfermeiros, auxiliares e técnicos). Cascavel, PR, Brasil, 2015.

\section{DISCUSSÃO}

Os resultados obtidos neste estudo vão ao encontro daqueles apresentados no robusto censo denominado "Perfil da Enfermagem no Brasil", conduzido pelo Conselho Federal de Enfermagem (COFEN) em parceria com a Fundação Oswaldo Cruz (Fiocruz). Apontou que a enfermagem é predominantemente feminina e apresenta maior escolaridade do que o mínimo necessário ao desempenho de suas atribuições ${ }^{(21)}$. Estas mesmas características também são apresentadas pelos participantes de um estudo desenvolvido em um hospital escola público do interior do Estado de São Paulo ${ }^{(13)}$.

A frequência de atuação dos profissionais de enfermagem em PCRIH surpreendeu as expectativas dos pesquisadores, talvez pelo fato de que as unidades em que os profissionais deste estudo atuam apresente grande quantitativo de pacientes classificados como sendo de cuidado semi-intensivo e intensivo ${ }^{(22)}$.

Foi possível perceber, na avaliação teórica, que os participantes desconheciam as bases teóricas para detectar PCR, sendo que muitos dos enfermeiros, técnicos e auxiliares afirmaram a necessidade de procedimentos proscritos e que já não faziam parte das recomendações pelas Diretrizes 2010 da $\mathrm{AHA}^{(16)} \mathrm{e}$ pela Diretriz da SBC ${ }^{(16)}$, como é o caso do procedimento "ver, ouvir e sentir se há respiração".

Um único estudo descritivo e sem intervenção educativa realizado em Minas Gerais, comparou o conhecimento teórico sobre PCR apresentado por enfermeiros de diferentes unidades assistenciais intrahospitalar ${ }^{(15)}$. Na pesquisa, aponta-se que a média de acertos dos profissionais das unidades de emergência (centro cirúrgico, unidade de terapia intensiva para adulto e pronto socorro), comparada com aquela obtida pelos enfermeiros de unidades de internação (clínica médica e unidades cirúrgicas), foi maior no que tange aos sinais clínicos de reconhecimento da PCR. Isso talvez possa ser explicado pelo fato de trabalharem mais diretamente com indivíduos em situações instáveis de saúde. Todavia, vale ressaltar a importância dos profissionais manterem-se atualizados, pois o perfil dos pacientes internados das unidades de internação do presente estudo, apresenta características de instabilidade, e maior número de PCRIH do que o esperado.

Por outro lado, em pesquisa desenvolvida na cidade de Campinas (SP), com o objetivo de identificar o 
conhecimento dos profissionais de enfermagem em unidades não hospitalares de urgência/emergência sobre PCR, identificou-se que mais da metade dos participantes não responderam corretamente a questão sobre deteç̧ão da $P C R^{(23)}$.

Sendo assim e, fortalecendo a ideia de que intervenções educativas colaboram na melhoria do conhecimento teórico dos profissionais, os enfermeiros ( $p$-valor 0,018 ), técnicos e auxiliares ( $p$-valor $<0,0001)$ apresentaram aumento significativo na média de pontos na questão sobre o referido tópico no momento pós-intervenção, assim como em outros estudos ${ }^{(13-14)}$.

Ademais, as intervenções educativas também produziram efeitos positivos no conhecimento sobre a primeira atitude após constatar PCR e sobre a sequência correta do SBV para adulto e, entre técnicos e auxiliares, as intervenções resultaram em melhora significativa da média de pontos em todas as questões que pertenciam ao grupo de temática sobre SBV. Em pesquisas congêneres ${ }^{(13-14)}$, as intervenções educativas também corroboraram para melhora dos resultados obtidos pelos profissionais no pós-teste teórico, em relação aos assuntos supracitados.

Seguindo o disposto, observou-se que nas questões sobre SAVC o ponto crítico do saber permeou o assunto "via de administração dos fármacos" (questão com maior diferença estatística entre a média de pontos pré/pós-teste). Apesar de enfermeiros também terem apresentado resultados significativos ( $p$-valor 0,008), a média de pontos no pós-teste foi, especialmente significante, para técnicos e auxiliares ( $p$-valor $<0,0001)$. Em estudos realizados em Recife $(P E)^{(14)}$ e em Campinas (SP) ${ }^{(13)}$, questões relacionadas à administração dos fármacos também estiveram dentre aquelas com maior diferença de acertos no pós-teste, depois dos profissionais de Enfermagem terem participado do treinamento.

A avaliação global da efetividade das ações revelou que, todos os profissionais tiveram melhora significativa do desempenho após terem participado do treinamento, corroborando com outros estudos ${ }^{(13-}$ 14). Não obstante, cumpre salientar que estudos com percurso metodológico igual a este são consideravelmente escassos na literatura ${ }^{(23)}$, o que dificulta uma análise comparativa mais abrangente.

No universo intra-hospitalar, frequentemente, membros da equipe de enfermagem são os primeiros a se depararem com uma situação de $\mathrm{PCR}^{(24-25)}$. Assim, treinamentos e capacitações com foco na atualização e resgate do saber profissional podem melhorar o desfecho da PCRIH ${ }^{(3,5,25)}$. Além disso, com base nas evidências científicas disponíveis, as diretrizes atuais da $\mathrm{AHA}^{(10)}$ para parada e ressuscitação cardiopulmonar apontam ser necessário dar especial atenção às PCRIH, fortalecendo a qualificação dos profissionais no intrahospitalar para que, possam melhorar os desfechos dos eventos ocorridos em seus cenários de atuação.

Com perspectivas para estudos futuros, compreende-se a necessidade de avaliações mais aprofundadas, como exemplo, a inserção de um modelo teórico para embasar a construção do programa educativo; a coleta de dados em diferentes períodos, no pós-teste, ampliando o tempo em relação ao utilizado neste estudo e, não apenas imediatamente após o treinamento.

Para além disso, intenciona-se, em outra fase do estudo, verificar possíveis correlações entre as características dos participantes (tal como escolaridade e tempo de atuação e formação profissional) e seus 
respectivos desempenhos nos testes teóricos é outra opção a ser considerada em pesquisas futuras.

\section{CONCLUSÃO}

Foi possível concluir que a intervenção educativa colaborou positivamente no conhecimento teórico dos profissionais de enfermagem sobre parada cardiorrespiratória, no grupo estudado.

Além disso, cabe destacar que se faz necessário o desenvolvimento de mais estudos sobre a temática abordada, pois pesquisas deste cunho podem subsidiar as estratégias gerenciais que visam qualificar o cuidado, fomentando a apropriação de conhecimento técnico-científico sólido por parte dos profissionais. Dessa mesma forma, é preciso compreender qual a influência das intervenções educativas (e fatores associados) não só no conhecimento teórico dos profissionais de Enfermagem, mas também em suas práticas laborais, quando da atuação em situações de PCRIH.

\section{REFERÊNCIAS}

1. Junqueira RMP, Duarte EC. Fatores associados à chance para a mortalidade hospitalar no Distrito Federal. Epidemiol Serv Saude [Internet]. 2013 [acesso em: 01 out. 2017];22(1):29-39. Disponível em: http://dx.doi.org/10.5123/S167949742013000100003.

2. Giacomini MG, Lopes MVCA, Gandolfi JV, Lobo SMA. Septic shock: a major cause of hospital death after intensive care unit discharge. Rev Bras Ter Intensiva [Internet]. 2015 [acesso em: 01 out. 2017];27(1):51-6. Disponível em: http://dx.doi.org/10.5935/0103-507X.20150009.

3. Bergum D, Haugen BO, Nordseth T, Mjølstad OC, Skogvoll E. Recognizing the causes of in-hospital cardiac arrest A survival benefit. Resuscitation [Internet]. 2015 [acesso em: 01 out. 2017];97:91-6. Disponível em:

http://dx.doi.org/10.1016/j.resuscitation.2015.09.395.

4. Nacer DT, Barbieri AR. Sobrevivência a parada cardiorrespiratória intra-hospitalar: revisão integrativa da literatura. Rev. Eletr. Enf. [Internet]. 2015 [acesso em: 01 out. 2017];17(3). Disponível em:

https://doi.org/10.5216/ree.v17i3.30792.

5. Girotra S, Nallamothu BK, Spertus JA, Li Y, Krumholz HM, Chan PS. Trends in Survival after In-Hospital Cardiac Arrest. N Engl J Med [Internet]. 2012 [acesso em: 01 out. 2017];367(20):1912-20. Disponível em:

http://dx.doi.org/10.1056/NEJMoa1109148.

6. Campanharo CRV, Vancini RL, Lopes MCBT, Okuno MFP, Batista REA, Atallah ÁN, et al. Advantages of a cohort study on cardiac arrest conducted by nurses. Rev Esc Enferm USP [Internet]. 2015 [acesso em: 01 out. 2017];49(5):762-6. Disponível em: http://dx.doi.org/10.1590/S0080-623420150000500008.

7. Ocen D, Kalungi S, Ejoku J, Luggya T, Wabule A, Tumukunde J, et al. Prevalence, outcomes and factors associated with adult in hospital cardiac arrests in a low-income country tertiary hospital: a prospective observational study. BMC Emerg Med [Internet]. 2015 [acesso em: 01 out. 2017];15(1):23. Disponível em: https://doi.org/10.1186/s12873-0150047-0.

8. Joshi M. A prospective study to determine the circumstances, incidence and outcome of cardiopulmonary resuscitation in a referral hospital in India, in relation to various factors. Indian J Anaesth [Internet]. 2015 [acesso em: 01 out. 2017];59(1):31. Disponível em: http://dx.doi.org/10.4103/0019-5049.149446.

9. Chen C-T, Chiu P-C, Tang C-Y, Lin Y-Y, Lee Y-T, How C-K, et al. Prognostic factors for survival outcome after inhospital cardiac arrest: An observational study of the oriental population in Taiwan. J Chinese Med Assoc [Internet]. 2016 [acesso em: 01 out. 2017];79(1):11-6. Disponível em: http://dx.doi.org/10.1016/j.jcma.2015.07.011. 10. American Heart Association. Destaques da American Heart Association 2015. Atualização das Diretrizes de RCP e ACE. Dallas: American Heart Association, 2015 [acesso em: 01 out. 2017]. Disponível em: https://eccguidelines.heart.org/wp-content/uploads/2015/10/2015-AHA-Guidelines-Highlights-Portuguese.pdf. 
11. Morrison LJ, Neumar RW, Zimmerman JL, Link MS, Newby LK, McMullan Jr PW, et al. Strategies for improving survival after in-hospital cardiac arrest in the United States: 2013 consensus recommendations: a consensus statement from the American Heart Association. Circulation [Internet]. 2013 [acesso em: 01 out. 2017];127(14):153863. Disponível em: http://dx.doi.org/10.1161/CIR.0b013e31828b2770.

12. Ministério da Saúde, Secretaria de Gestão do Trabalho e da Educação na Saúde, Departamento de Gestão da Educação na Saúde. Política Nacional de Educação Permanente em Saúde [Internet]. Brasília: Ministério da Saúde; 2009 [acesso em: 01 out. 2017]. Disponível em:

http://bvsms.saude.gov.br/bvs/publicacoes/politica_nacional_educacao_permanente_saude.pdf.

13. Bellan MC, Araújo IIM, Araújo S. Capacitação teórica do enfermeiro para o atendimento da parada cardiorrespiratória. Rev Bras Enferm [Internet]. 2010 [acesso em: 01 out. 2017];63(6):1019-27. Disponível em: http://dx.doi.org/10.1590/S0034-71672010000600023.

14. Lima SG, Macedo LA, Vidal ML, Sá MPB O. Educação Permanente em SBV e SAVC: impacto no conhecimento dos profissionais de enfermagem. Arq Bras Cardiol [Internet]. 2009 [acesso em: 01 out. 2017];93(6):630-6. Disponível em: http://dx.doi.org/10.1590/S0066-782X2009001200012.

15. Cunha CM, Toneto MAS, Pereira EBS. Conhecimento teórico dos enfermeiros de um hospital público sobre reanimação cardiopulmonar. Biosci J [Internet]. 2013 [acesso em: 01 out. 2017];29(5):1395-402. Disponível em: http://www.seer.ufu.br/index.php/biosciencejournal/article/view/17175.

16. American Heart Association. Destaques das Diretrizes da American Heart Association 2010 para RCP e ACE. Dallas: American Heart Association, 2010 [acesso em: 01 out. 2017]. Disponível em: http://www.heart.org/idc/groups/heartpublic/@wcm/@ecc/documents/downloadable/ucm_317343.pdf.

17. Gonzalez MM, Timerman S, Oliveira RG, Polastri TF, Dallan LAP, Araújo S, et al. I guideline for cardiopulmonary resuscitation and emergency cardiovascular care - Brazilian Society of Cardiology: executive summary. Arq Bras Cardiol [Internet]. 2013 [acesso em: 01 out. 2017];100(2):105-13. Disponível em:

http://dx.doi.org/10.5935/abc.20130022.

18. Alexandre NMC, Coluci MZO. Validade de conteúdo nos processos de construção e adaptação de instrumentos de medidas. Cien Saude Colet [Internet]. 2011 [acesso em: 01 out. 2017];16(7):3061-8. Disponível em:

http://dx.doi.org/10.1590/S1413-81232011000800006.

19. R Development Core Team. R: A Language and Environment for Statistical Computing. Vienna, Austria: the R Foundation for Statistical Computing. 2013.

20. Resolução № 466 do Conselho Nacional de Saúde, de 12 de dezembro de 2012 (BR) [Internet]. Aprova as diretrizes e normas regulamentadoras de pesquisas envolvendo seres humanos. Diário Oficial da União. 12 dez. 2012 [acesso em: 01 out. 2017]. Disponível em: http://bvsms.saude.gov.br/bvs/saudelegis/cns/2013/res0466_12_12_2012.html. 21. Conselho Federal Enfermagem. Perfil da enfermagem no Brasil: principais informações [Internet]. Curitiba: COREN/PR, 2015 [acesso em: 01 out. 2017]. Disponível em:

http://www.corenpr.gov.br/portal/images/lai/RelatorioConcisoPerfilEnfermagem.pdf.

22. Barbosa HB, Paiano LAG, Nicola AL, Fernandes LM. Nível de complexidade assistencial de pacientes e o quantitativo de profissionais de enfermagem. Revista de Enfermagem da UFSM [Internet]. 2014 [acesso em: 01 out. 2017];4(1):29-37. Disponível em: http://dx.doi.org/10.5902/217976929230.

23. Almeida AO, Araújo IEM, Dalri MCB, Araujo S. Theoretical knowledge of nurses working in non-hospital urgent and emergency care units concerning cardiopulmonary arrest and resuscitation. Rev Lat Am Enfermagem [Internet]. 2011 [acesso em: 01 out. 2017];19(2):261-8. Disponível em: http://dx.doi.org/10.1590/S0104-11692011000200006.

24. Luzia MF, Lucena AF. Parada Cardiorrespiratória do paciente adulto no âmbito intra-hospitalar: subsídios para a enfermagem. Rev Gaucha Enferm [Internet]. 2009 [acesso em: 01 out. 2017];30(2):328-37. Disponível em: http://www.seer.ufrgs.br/index.php/RevistaGauchadeEnfermagem/article/view/5638.

25. Heng KWJ, Fong MK, Wee FC, Anantharaman V. The role of nurses in the resuscitation of in-hospital cardiac arrest. Singapore Med J [Internet]. 2011 [acesso em: 01 out. 2017];52(8):611-5. Disponível em:

http://smj.sma.org.sg/5208/5208ra15.pdf. 